Österreichische Akademie der Wissenschaften / Austrian Academy of Sciences AAS WORKING PAPERS IN SOCIAL ANTHROPOLOGY

Volume 25

Haifa Al-Hababi

THE ART OF WOMEN IN 'ASIR

(SAUDI ARABIA)

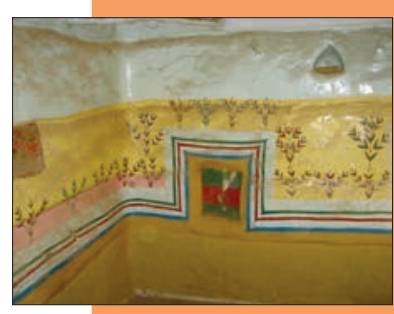

Band 25

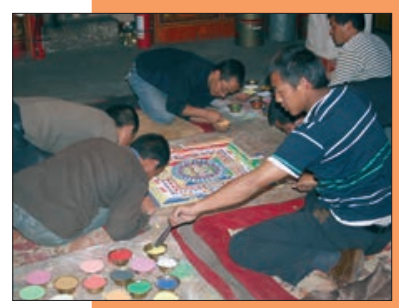




\section{AAS Working Papers in Social Anthropology / \\ ÖAW Arbeitspapiere zur Sozialanthropologie}

ISBN-Online: 978-3-7001-7316-8

DOI: $10.1553 /$ wpsa25

Wien 2012

Editors / Herausgeber:

Andre Gingrich \& Guntram Hazod

(C) Institut für Sozialanthropologie

Zentrum Asienwissenschaften und Sozialanthropologie

Österreichische Akademie der Wissenschaften

Apostelgasse 24

A-1030 Wien

Fax: 01/ 51581-6450

E-Mail: sozialanthropologie@oeaw.ac.at 


\title{
THE ART OF WOMEN IN 'ASIR (SAUDI ARABIA)
}

\author{
Haifa Al-HabABi
}

\section{The Architecture and Painting Tradition of 'Asir*}

It is unclear when the women of 'Asir began the tradition of painting their interior home walls with vibrant frescoes and murals. According to the fieldwork research conducted in 1991 and 1992 by Professor Ghithan Ali Jrais, it states that he saw houses that were approximately three to four hundred years old and some of which had different colours and patterns inside. ${ }^{1}$ This finding was also stated in many travel books such as those of Sir Kinahan Cornwallis, ${ }^{2} \mathrm{M}$. Tamizier $^{3}$ and ST.J.B. Philby ${ }^{4}$ and therefore confirms that the tradition is many generations old. When questioned the 'Asiri women reveal they were taught to paint in their unique way by their mothers and their grandmothers before them. The architecture of the 'Asir region is rich, but the interiors of these beautiful houses are in danger of becoming extinct before the world learns much about them.

The architecture of Abha and Sarat in 'Asir is different from other areas of the Kingdom of Saudi Arabia on both its exterior and interior. 'Asir is known for its abundant rainfall and severe cold winters. Therefore the buildings have been adapted with strong foundations and walls, made by piling a row of rocks around the external walls so as to protect them from heavy rain, hence reducing its effects and that of hail on the mud walls. This method has helped to ensure the survival of these buildings for long periods of time, often hundreds of years.

In the mountainous highlands, the buildings were originally built from stone for further protection and strength. Windows were small and narrow, and were located in the inner part of the wall to allow the entry of sunlight but prevent the entry of cold winds. The conical shape of the building provided further resistance to winds, which shows a strong correlation between the environment and its architecture.

'Asir's society is an inherited social coordination that encourages all family members to work. Every member fits into a devised working system that is managed by a family elder. The main source of 'Asiri families is agriculture, and it is the responsibility and duty of the male family members to conduct the farming. Women carry out the domestic tasks, although they help the men during the threshing and harvesting seasons. In addition to this, it is the women who complete the entire process of creating the highly structured interior wall decorations, which is the most outstanding architectural feature of the house. Even though the men build the houses with the help from other members of their tribe or village and in some cases hiring people, but their building role ends after fitting the doors and windows. At this point the woman takes over and her role would involve all the remaining jobs such as plastering, smoothing the walls and

\footnotetext{
* The present contribution is based on a paper presented by the author at the Institute for Social Anthropology of the Austrian Academy of Sciences, May 12, 2011.

${ }^{1}$ Jrais, G. 2002. Studies in Recent History of Assir, Jeddah, Saudi Arabia, p. 48.

${ }^{2}$ Cornwallis, K. 1976. Asir before World War 1: A Handbook, New York, p. 32f.

${ }^{3}$ Tamisier, M. 1840. Voyage En Arabie. Sejour Dans Le Hedjaz - Campagne D'Assir. Paris: L. Desessart.

${ }^{4}$ Philby, J. 1952. Arabian Highlands, Washington D.C., p. 59.
} 
floors, decorating and colouring the walls. When Aljazi ${ }^{5}$ was asked why the walls were painted by women, she answered that "this activity is perceived as artistic and feminine, so men reject it with scorn, murals are a woman's work". This attitude and way of thinking is still prevalent in the 'Asiri society. According to this concept a woman feels that the house is her property and thus the attention she has to give to her house in terms of cleanliness, decoration and colouring gives her the freedom to discover how to express herself in her domestic life. Therefore the house, which is the centre of family life, is considered the woman's realm. As a consequence mural paintings are a woman's prerogative in 'Asir, expressing her unique, intimate relationship with the house and standing as her response to being excluded from public life.

According to Um 'Ali:6 "We used to go into the mountains to collect gypsum, and sometimes we had to go down into caves to find it. Occasionally we had to crawl, and lumps of rock could fall on a woman". This shows the determination of the 'Asiri woman to decorate and colour her house despite the risks that she was exposed to. Moreover, it is an indication that there is some courage in competition, or a challenge to prove the woman's capabilities and personality among the women of the city, village or tribe.

Murals come across as a miracle, a survival from primitive times. In traditional societies, many actions are explained by statements such as "we have always done it this way, this is how our mothers worked, it's beautiful". It is possible that the older women who were questioned were repressing their frustrated efforts at orally communicating their emotions, feelings and intuitions, while for the young the priority is to learn how to carry out this aesthetic tradition without necessarily understanding how it came about. The hand perhaps relays truths and joys that the tongue leaves unstated. As Tisseron pointed out, everyone senses that a drawing can be a way to "state one's case", and the importance of this means of communication can be seen in the slogan daubed on a wall in Paris in May 1968: "Walls have a tongue". These murals are now in the hands of men who get paid $£ 1$ per metre for painting them. The drift from traditional painting methods is just one of the signs of the decline in the art of 'Asir. In many parts of the region, the painting tradition has virtually disappeared. The inhabitants try to blame it on civilisation and the fact that they have different kinds of houses, modern wall paintings and curtains, none of which is a major reason.

In the regions where this aesthetic tradition is dying out or is extinct, the most striking decoration in the past was the one that was associated with the reception room. My explorations of ruined houses and the few eyewitness accounts from the period of 1922-1970, seem to indicate that this was once the only room to be decorated. In the best cases, the walls and stairs might be covered with strips of colour, but this was not fresco in the sense in which the locals understood it. The decoration served to differentiate the reception room from the other rooms.

\section{The process of house decoration by the women}

The decoration inside houses is a self-directing art, in that no one asks a woman what to do or tells her what she should draw. It is an artistic symbol of the woman's taste in this connection. Although shapes such as "al-mosht" (comb) and "al-shabka" (net) are popular. According to Aljazi, "innovation is important to the woman who decorates, she will stop decorating if she does not renew

\footnotetext{
${ }^{5}$ Aljazi: one of three femals artists still painting frescoes in Rijal Almaa.

${ }^{6}$ Umm 'Ali: one of the older generation who used to work with colours that obtain from the surrounding environment in Sarat.
} 
and innovate shapes". Women chose to make their decorations as vibrant and full of life as possible. This is one of the means that a woman had in expressing her individuality and her competitiveness. This shows the importance given to the decoration of houses, which has now been obliterated by the use of modern paint. That is to say that there are no women left who are not using modern paint.

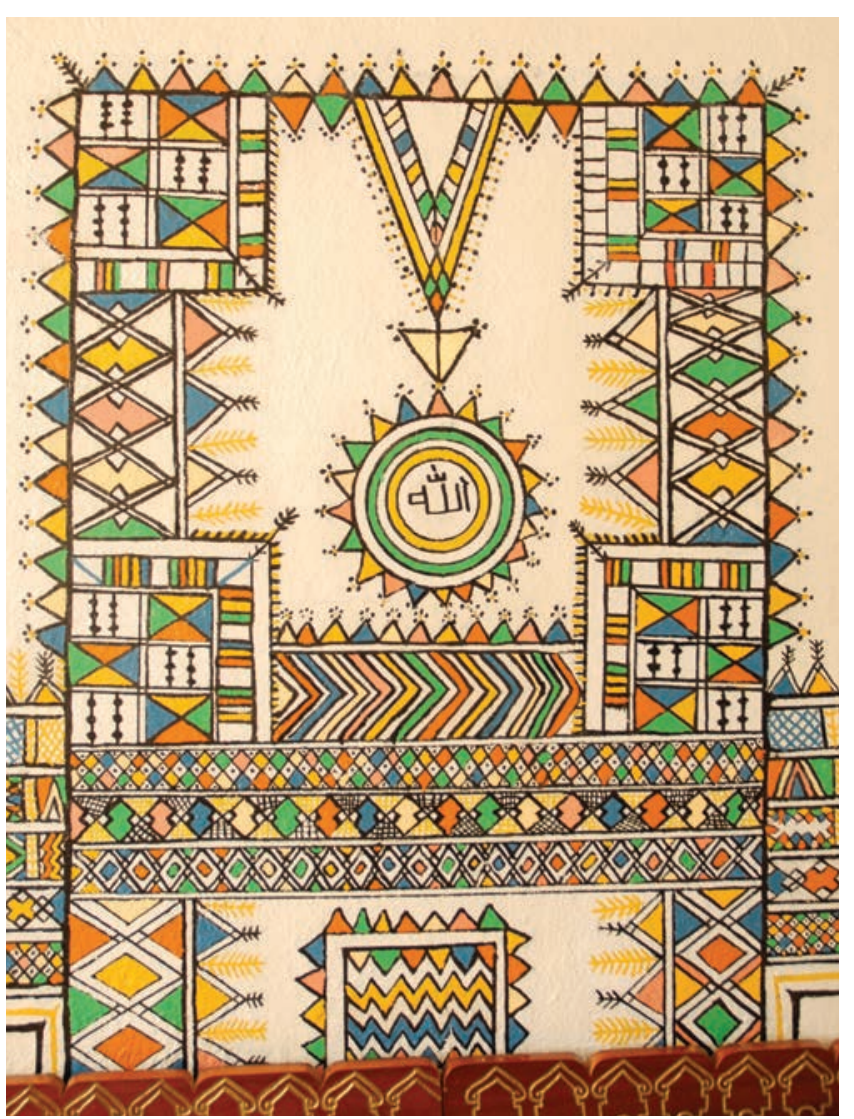

1. Painting by the female artist Aljazi.
The art of the mural has evolved traditionally in a manner described by the women in 'Asir in the following terms: "My mother did the same and my mother's mother too". Murals were made under the guidance of talented women. There is evidence that within the collective process of a woman's painting of the house, individualistic contributions are soon absorbed into the overall effort. When a refined, unified aesthetic tradition arises, this is generally because one or several talented painters were recognised by the group and their skill becomes a point of reference for the group as a whole, and so a distinctive style is created.

This painting can be done by the housewife, or a woman specialised in the field, in that an artist comes to paint the wall. It can be individual or collective, but it is more often collective than individual.

In this collective process, a group of women work together in a room under the supervision of a well-known female painter. Each one does what the others do and in effect they work as a team under the instruction of an acknowledged expert. I should clarify that an expert female painter is a woman who has taken up painting as a profession.

The owner of the house being decorated does not prepare coffee, tea or meals, as these are brought by the women who come to assist her. They bring cakes, sweets, raisins, including local food called cujart and qarmash. My own observation of the manner in which the women work shows that this process not only answers the need for efficiency, but also plays a didactic role in developing painting skills: knowledge is transmitted through sharing. What these traditional painters do best is to repeat, improve and eventually perfect something that a talented artist had created in the first instance. Women learn through imitation of the most authoritative woman, and therefore an entire regional art form is born. These women follow the direction and lead of the elderly women in the village throughout the process. The women always begin with the outlines, then colour in the patterns that have been marked out. The brushwork is a delicate procedure that requires much training. The pressure is determined by the arm, since the painter necessarily works with her hand raised and cannot lean on the wall. The drawing brush must be round, pointed, flexible and made of plenty of hair bristles to do the job. This is why in the past drawing brushes were made from hairs taken from goats' tails and tied into a bundle then fastened onto a wooden stick. The 
sizes would differ depending on the purpose of its use. For example, the drawing brush used to draw lines is different from the one used for colouring. Consequently the ones they used for small details ranged from the broadest to the finest with coloured dots that were used as a guide to the assistants as they coloured. According to Um 'Ali, who worked with the natural pigments that were used in the past, colouring materials were obtained from the surrounding environment and were prepared and used as follows.

White Paint: This is called gypsum and is made from layers of lime brought from the mountains. The lime is diluted with water after it has been powdered by means of a stone mill made with a concave section linked to a spindle-shaped grinder ( $r a h a)$. Added to it at the same time is glue (alsamg alarabi) that is collected from trees such as Al-Talah, which is pounded until it becomes very soft. The mixture of the lime with the glue forms a mixture known as al-Shuwayt, which the walls are painted with and gives them a smooth, soft, white and shiny appearance.

Green Paint: Known as alfalfa derived from grass (al-Qadab). It is used either by scrubbing the grass directly onto the walls, or by squeezing it and adding the water and the glue obtained to the consistency of the white paint described earlier.

Blue Paint: known as Indigo and is named after the blue dye that is derived from the plant indigofera tinctoria (nela). This used to be sold in the local markets and is either soaked in water and used as it is, or used after the addition of some glue.

Black Paint: The woman pounds some alfalfa grass and then squeezes and strains it. A candle or kerosene lamp is then lit and a plate or similar receptacle is placed in the flame to gather soot, which is then added to the alfalfa grass to turn it black. This method is in addition to the use of black tar (qutran), extracted from al-Athel tree which is burnt whilst green to produce a dripping oil.

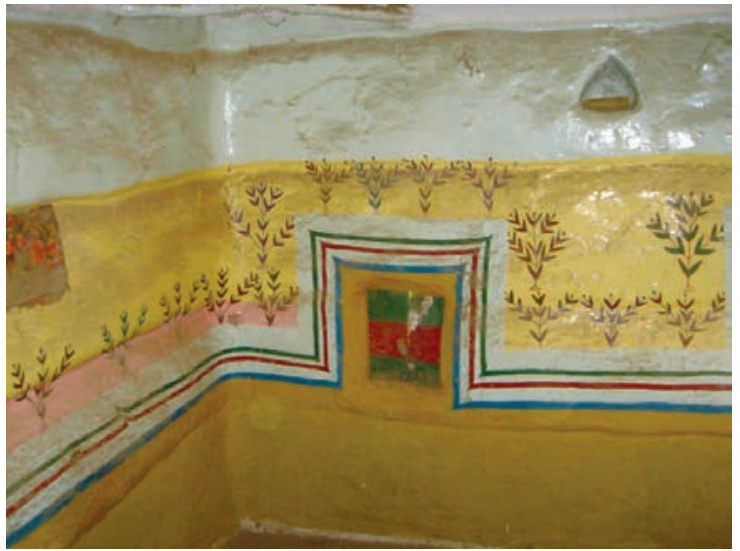

2. House in Blad Qahtan.

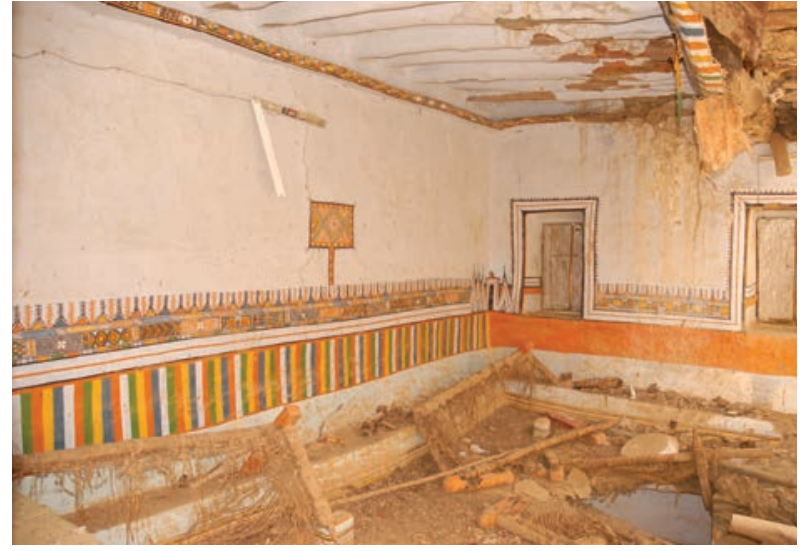

3. Painting by the the artist Fatma Abo Gahas.

Other powder colours were brought from Adan in the south of the Arabian Peninsula. Different types of red and black mud were also used for colouring; all the colours were used independently, without being mixed with one another. This imposed a limited choice of colours, depending on what pigments were locally available.

These traditional colours were used until the 1970's when the women of 'Asir discovered the use of modern paint. They pointed out that the replacement of traditional pigment with artificial wall pigment (buya) eliminated the long and difficult task of acquiring and preparing the colours prior to the act of painting. 


\section{Colouring Methods}

The woman starts the decoration and colouring of the house by first painting the internal walls white. Then she starts to decorate the house, using other colours according to her own taste to produce a relaxing and pleasant effect. The windows are painted both internally and externally while the doors are painted with tar oil. Some women paint the floors and stairs of the house with alfalfa tree. The woman repeats the decoration and painting process during the Islamic holy month (Ramadan) or on special occasions, so that the house reflects her artistic ability and her efficiency as the lady of the house. It usually suffices to paint the exterior of the house with white paint, particularly around the windows. The woman also undertakes this work, using ladders to reach the uppermost parts of the exterior walls. In certain cases, a professional woman specialising in such work may undertake the task if the owners can afford such an expense.

\section{Analysis of the decoration}

From reading Lippens ${ }^{7}$ we might think that geometric patterns had been adopted as a last resort. But if we do accept that figurative art has been dogmatically rejected, we still need to examine the very nature of the geometric patterns used, which set this aesthetic tradition apart from other Saudi art. In this case, all women are painters, some more talented than others of course, but they are all capable of decorating their houses and experimenting with combinations of the protogeometric patterns used in 'Asir.

When attempting to understand and situate a cultural production, we naturally turn to a comparison of the features that we find recognisable and logical according to our own experience. In that case the following question arises: why is there an exclusive use of straight geometric figures rather than curved ones? The absence of curves is the distinguishing mark of such compositions.

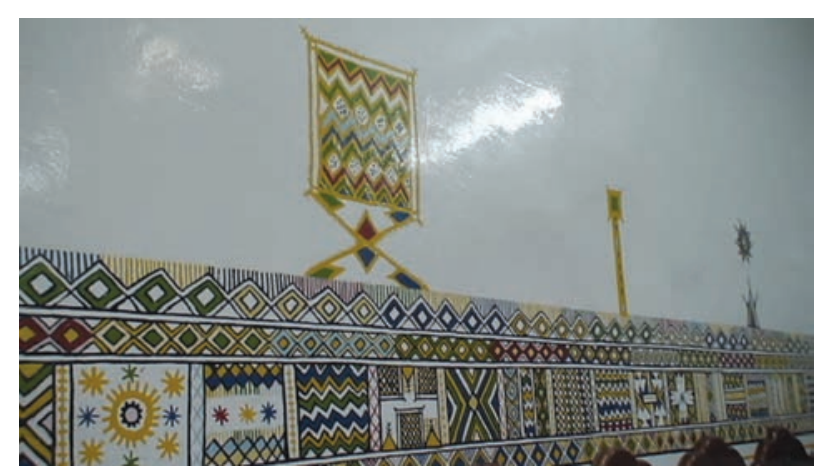

4. Painting by Fatma Abo Gahas in her son's house. However that wasn't the opinion of the women and men in the field of art that I interviewed during my trip to 'Asir. Instead, they linked this to the art of weaving and pointed out the striking similarity between these murals and the Arab-Islamic art of textile design. Furthermore they added that this connection can also be seen in the fact that all such paintings directly reflect technical limitations in the looms used in

Saudi Arabia. These frame less horizontal looms with one line of heddle and a short warp are used by all nomads in the Middle East with slight regional variations. But my argument was that there is a big deference between using a drawing brush that can follow the painter's hand, and a warp and weft that naturally lead to vertical and horizontal lines which made the textile designs become geometric. This included triangles, diamonds, zigzags and their derivatives. It is impossible to weave a circle, so that is accordingly replaced by a lozenge, the sides of which are rather reminiscent of the pixels of a digitised image on a computer screen.

While human nature has always looked for new forms of decoration, the security created by

\footnotetext{
${ }^{7}$ Lippens, P. 1956. Expedition en Arabie Centrale, Paris, p. 87.
} 
the pacification of the region, higher incomes and more leisure time have opened the way to the acquisition of status symbols. The possession of a beautiful, solid house with decorative murals

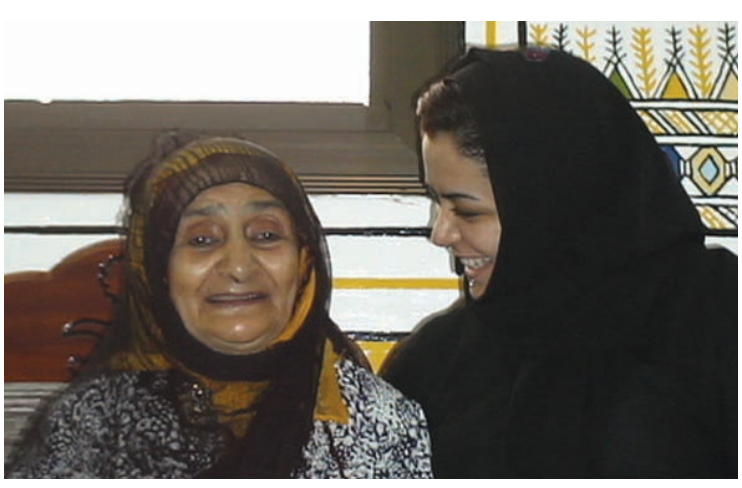

5. The author and Fatma Abo Gahas (d. 2010). is a prime example. It is the women who devote their skills and reflect their personalities to this objective. Even though, in the words of LeroiGourhan, "the criteria behind any decoration lie more in the decorator's intentions rather than in the elements used, it is still interesting to examine their original sense". However, ethnographers in this field came up against the same obstacles as cave-painting specialists. A barrier of ignorance excludes any real understanding. The only difference is that we can find out if our impressions match those of the women painters. But we have already seen that these tongue-tied artists describe their work with subjective judgements such as "it's beautiful", which clearly show how limited their understanding of an aesthetic tradition is and that it has never been seriously discussed by those involved.

But the highly simplified and apparently unfinished graphic designs that can be found in the oldest abandoned houses suggest that there was more to them than just decoration. Were these residual traces determined by some symbolic framework? As with tattoos, the patterns used may be a by-product of an older system of signs created by illiterate societies at the beginning of the historical period of the Ottoman from 1871-1917 and the Idrisi emirate period of 1918-1920. Such symbols were described by André Malraux as "primordial forms".

Subsequent generations then enriched them by assimilating them into their own experience. Once these signs had been mingled with newer, more highly evolved images, they became open to different interpretations, while retaining their primordial structures. ${ }^{8}$

- Haifa AL-HABABI is a PhD student at the School of Oriental and African Studies SOAS London University in the Department of Art and Archaeology, UK. Her primary research is on the "The Art of the Woman of Asir, Saudi Arabia". She is writing her first book about her trip to Asir and in particular her field experience with women in Asir.

\footnotetext{
${ }^{8}$ Aljaze convincingly explains the origin of these graphic designs in terms of art. An interesting example is provided by the numerous tactic form patterns used in friezes. In interiors, the frieze of a room is the section of wall above the picture rail and under the crown mouldings or cornice. By extension, a frieze is a long stretch of painted, sculpted or even calligraphic decoration in such a position, normally above eye-level. Frieze decorations may depict scenes in a sequence of discrete panels. The material of which the frieze is made of may be plasterwork, carved wood or other decorative medium.
} 